\title{
Impacto da crise económica em Portugal: Caos, previsões e conservadorismo
}

\section{Impact of the Economic Crisis in Portugal: Chaos, Forecasts and Conservatism}

\author{
Eduardo Manuel de Almeida Leite ${ }^{1}$
}

$1 \quad$ E-mail: eduardoleit@gmail.com; Sociedade Educativa do Brasil (Soebras); Centro de Estudos da População, Economia e Sociedade (CEPESE)

\begin{abstract}
Resumo
O presente texto aborda os temas da previsão e do conservadorismo, no contexto da atual crise económica e do seu impacto em Portugal, desde 2008. O tema das previsões é apresentado através de uma metáfora, recorrendo aos princípios da teoria do caos e do efeito-borboleta de Edward Lorenz, normalmente aplicados nas previsões meteorológicas, para ilustrar a crise económica e financeira em Portugal. O tema do conservadorismo é apresentado por meio de uma analogia com o pensamento de Kuhn. A metáfora mostra que as previsões económicas e financeiras falham, frequentemente, na antecipação de uma crise, entre outros aspetos, devido às seguintes causas: Erros na avaliação e diagnóstico do problema, devido à dificuldade em identificar e compreender os sinais e as evidências, por vezes complexas. Quanto ao conservadorismo, a analogia com o pensamento de Kuhn deixa clara a resistência à mudança; a negação dos factos inconvenientes para as carreiras dos analistas e dos decisores; a persistência no modelo por dificuldade em responder aos erros paradigmáticos.
\end{abstract}

Palavras-chaves: Avaliação; Crise; Efeito-borboleta; Portugal; Previsões.

\begin{abstract}
This paper addresses the themes of forecasting and conservatism in the context of the current economic crisis and its impact in Portugal since 2008. The theme of the forecasts is presented through a metaphor, using the principles of chaos theory and of Edward Lorenz's butterfly effect, usually applied in weather forecasting, to illustrate the economic and financial crisis in Portugal. The theme of conservatism is presented through an analogy with the thinking of Kuhn. Metaphor shows that the economic and financial forecasts fail, often in anticipation of a crisis, among other aspects, due to errors in the assessment and diagnosis of the problem because of the difficulty in identifying and understanding the often-complex signs and evidence. As for conservatism, analogy with the thinking of Kuhn illuminates resistance to change -- the denial of inconvenient facts for the careers of analysts and decision makers and persistence in following the model because of difficulty in answering for paradigmatic errors.
\end{abstract}

Keywords: Evaluation; Crisis; Butterfly Effect; Portugal; Forecasts.

\section{Introdução}

Impacto da crise económica em Portugal: Caos, previsões e conservadorismo

Em setembro de 2008, num parque localizado no centro de Manhattan, Nova Iorque, um panapaná pairava sobre as plantas e flores, debaixo de um sol encoberto pelas nuvens, pronunciando o fim do verão. O fenómeno, raro, tornou-se conhecido no mundo e atraía inúmeros visitantes ao local. Com os olhos 
postos no céu, os visitantes mais pareciam assistir a uma adaptação para balé do romance de Tolstoy, AnnaKarenina, em exibição na vizinha Broadway, do que uma migração de borboletas.

Enquanto isso, antecipando a chegada do outono boreal, os jardineiros alinhavam meticulosamente os técnicos para tratar dos canteiros de flores e plantas, tendo em vista enfrentar uma diminuição das temperaturas médias e, mais tarde, as chuvas do inverno. De facto, com a aproximação do outono, os jardins ameaçavam despir-se, apresentando já alguns sinais de perda de fulgor e exuberância das estações mais quentes, visíveis, por exemplo, através de algumas folhas amareladas caídas no chão. Apesar da eficácia dos catadores, as folhas que caíam nos lagos tornavam-se difíceis de alcançar e de ocultar, ameaçando cobrir os espelhos de água, onde os patos de penas reluzentes, muito bem alimentados pelos turistas, nadavam tranquilamente sobre as carpas koi de tonalidade laranja, que contrastavam com o fundo escuro do lago.

Preocupados com a situação e aproveitando a já pouca presença de insetos, aves, roedores, entre outros frequentadores de época do parque, os jardineiros facilitaram o uso de agrotóxicos por parte dos floricultores, agrónomos e demais pessoal técnico afecto aos jardins e canteiros. Era importante prolongar a vitalidade das plantas e flores que evidenciassem sinais de enfraquecimento, por forma a evitar a respetiva queda e revelar as debilidades latentes do parque. Prolongando a vitalidade das plantas e flores, manteriam a boa aparência e apresentação dos jardins, que ajudariam, essencialmente, a fixar as borboletas. As borboletas, por sua vez, garantiriam os espetáculos de dança e cor, traduzindo-se em receitas para os jardineiros, no sustento dos patos e carpas, em oportunidades para os roedores, assegurando, desta forma, o equilíbrio do ecossistema.

Todavia, para surpresa de muitos, certo dia as borboletas apresentaram sintomas de doença, como tonturas, taquicardia, palpitações e alterações de voo. Ansiosas e com receio de se precipitarem no solo, as borboletas bateram desesperadamente as asas, efetuando movimentos desregulados de voo. Simultaneamente, sentiu-se um calafrio no parque, sobressaltando todos nos jardins. Impulsionada pelas condições meteorológicas do outono que já se adivinhava, a massa de ar frio propagou-se rapidamente a todo o parque, alcançando o Rio Hudson e desaguando, por via deste, no Oceano Atlântico. Com a entrada no oceano, temeu-se que a massa de ar frio aumentasse exponencialmente a sua força, ameaçando transformar-se numa tempestade, atingir a Europa Ocidental, particularmente a Península Ibérica.

Alarmados com a raridade do fenómeno, de consequências ainda desconhecidas, os meteorologistas americanos apressaram-se a difundir um alerta laranja aos seus congéneres europeus, advertindo-os para os eventuais prejuízos que a tempestade poderia causar nos parques e jardins da Europa. O teor do texto enviado pelos meteorologistas americanos aos europeus, referia, e previa, aproximadamente o seguinte: Há momentos os computadores do sistema de previsão das condições meteorológicas e prevenção de intempéries do central parque, identificaram a formação de uma massa de ar frio, cuja origem se pensa estar relacionada com uma doença súbita das borboletas. Registámos a queda de folhas e pétalas de flores, bem como o derrube de árvores de pequeno porte. A massa de ar frio propagou-se ao Rio Hudson e estamos a registar um aumento significativo na sua velocidade e deslocamento em direção ao Oceano Atlântico. Em função desta alteração, e com a entrada no Oceano Atlântico, tememos que a massa de ar frio possa causar a formação de uma tempestade de grandes dimensões e atingir os jardins da Europa, 
designadamente a Península Ibérica, mais especificamente Portugal (Adaptado dos princípios meteorológicos de Lorenz, 1993).

Neste quadro dramático, é interessante estabelecer aqui uma ponte com as ideias expressas por Elisabeth Kübler-Ross e os desenvolvimentos seguintes. Kübler-Ross não foi uma jardineira ou meteorologista, mas sim uma psiquiatra, cujo trabalho trata os comportamentos e as atitudes dos pacientes perante a morte. Apesar disso, o seu trabalho tem muito que nos ensinar sobre o comportamento das borboletas americanas, a formação da tempestade e o impacto da crise em Portugal. Em On Death and Dying, Kubler-Ross (1969) parte da hipótese de que os seres humanos passam por cinco fases psicológicas distintas antes da morte: negação, raiva, barganha (ou pensamento mágico), depressão e, finalmente, aceitação.

As fases sugeridas por Kubler-Ross (1969), podem ajudar a iluminar as consequências da tempestade nos jardins portugueses. Com efeito, inicialmente os jardineiros portugueses procuraram negar a aproximação da tempestade, desmentindo os meteorologistas, aproveitando o facto de estes não beneficiarem da melhor reputação junto da opinião pública, em consequência das falhas frequentes nas previsões do tempo. Porém, mais tarde, vendo com mais atenção e detalhe as imagens de satélite, foi possível identificar perfeitamente a formação da referida tempestade. Logo, os jardineiros portugueses lá se conformaram com a ideia de que uma fatalidade estaria eminente, sentindo grandes dificuldades em esconder as evidências das populações. A reação foi de fúria com os congéneres americanos, tanto jardineiros, como meteorologistas.

De qualquer forma, em declarações à nação, os jardineiros portugueses sugerem que o impacto da tempestade em Portugal seria pequeno e que, além do mais, o jardim português não pode comparar-se aos grandes parques americanos. Portanto, concluem os jardineiros portugueses, o pouco que viesse a sentirse em Portugal seria irrelevante, culpando novamente os jardineiros americanos, e o uso de agrotóxicos, por toda esta confusão e alarme. Pese embora as evidências, numa tentativa de acalmar as populações, os jardineiros portugueses mantiveram a posição inicial de que Portugal era diferente da América. Todavia, pouco a pouco, os jardineiros portugueses foram tomando consciência da inevitabilidade de Portugal ser atingido pela tempestade e dos estragos que isso causaria no jardim à beira mar plantado. Os jardineiros lá foram tomando algumas medidas cautelares, avulso, sempre recusando a ajuda de uma tróica de jardineiros de fora, que entretanto se havia colocado à disposição de Portugal. Desde que, claro está, os jardineiros portugueses se submetessem às políticas agrícolas Europeias em geral, princípios de jardinagem em particular, liderados pela Alemanha.

Não houve, porém, entendimento e o dia "D" chegou, devastando quase por completo Portugal. Os efeitos da tempestade, são, ainda hoje, visíveis no mais pequeno canteiro do interior do país, até ao jardim botânico da capital, Lisboa. Daí à depressão, decorreram apenas alguns dias. A cooperativa dos jardineiros portugueses sentindo-se impotente para lidar com a situação, aceitou incondicionalmente a vinda de uma tróica de jardineiros e de alguns meteorologistas estrangeiros para tomarem conta da ocorrência.

Em função dos novos métodos de jardinagem, a fauna portuguesa apresenta grandes dificuldades de adaptação e sobrevivência. A generalidade das borboletas portuguesas deixaram de ter ambiente no seu 
próprio jardim, sendo forçadas todos os dias a procurarem outros jardins para exibirem as suas cores vivas e os seus dotes de bailarinas. Ilustrado desta forma, parecem não restar dúvidas quanto às causas e consequências da tempestade. Na prática, o uso de agrotóxicos para melhorar a apresentação das flores e plantas, teve um efeito perverso em todo o ecossistema do parque. Analisando a saúde das borboletas, verificou-se que não suportaram a queda das temperaturas do outono, nem a falta néctar das flores. $\mathrm{Na}$ realidade, o néctar produzido pelas flores, além do baixo teor de outros nutrientes, como os aminoácidos, proteínas e vitaminas, já não apresentava a qualidade suficiente capaz de fornecer o açúcar e a água, bastantes para alimentar as borboletas. Acresce que os produtos tóxicos usados para rejuvenescer as plantas e flores no outono, envenenaram algumas borboletas, que contagiaram as outras. Em consequência, as borboletas começaram a sentir dificuldades em viver neste ambiente, entrando num estado de stresse grave, traduzido nos batimentos irregulares das suas asas.

Todavia, caso o sistema de avaliação e prevenção de intempéries tivesse funcionado na América, ou na Europa, poder-se-ia ter antecipado a tempestade. $\mathrm{Na}$ verdade, os sinais de que um incidente poderia estar iminente, eram por demais evidentes, sendo de destacar entre causas naturais e humanas, as seguintes:

i. O jardim já não apresentava o fulgor de outros tempos, por falta de calor do sol que se despedia do parque com o fim do verão;

ii. $\mathrm{O}$ arrefecimento das temperaturas pela aproximação do outono, deixava marcas visíveis no parque através das folhas caídas no solo, especialmente àquelas que caíam na água, por serem mais difíceis de remover;

iii. O uso de agrotóxicos melhora a apresentação do parque, mas tem consequências para a saúde da fauna.

iv. A itinerância dos habitantes do parque, apresenta o risco de contágio e efeitos colaterais, como, de resto, se verificou na saúde das borboletas e na propagação deste efeito, através das correntes e das condições climatéricas;

v. Os patos estavam gordos demais e com dificuldades em movimentarem-se por causa das folhas que atolavam os lagos. Além disso, os patos desconheciam os perigos do fundo dos lagos onde nadavam, por serem escuros demais para a sua visão;

vi. A cor laranja das carpas koi, indiciava o perigo nos lagos de águas turvas e sujas de folhas;

vii. As borboletas precisam de sol quente, luz transparente e de néctar para terem energia suficiente que, por sua vez, garanta o voo e, consequentemente, os visitantes.

Apesar das evidências, as previsões falharam na avaliação. Por fim, a tempestade foi uma realidade, atingindo a América e, posteriormente, Portugal tão violentamente, que causou o caos no jardim à beira mar plantado. Assim, no lugar onde anteriormente dominava a boa disposição, bom tempo, sol quase todo o ano e magníficas plantas, flores e borboletas, restam agora flores e plantas caídas, canteiros por recuperar e terminar. Inclusive os patos estão a escassear por causa dos destroços da tempestade e da falta de limpeza dos lagos. Mais grave ainda, as borboletas estão a partir e os espetáculos a terminarem. Em resultado da tempestade em Portugal, o jardim está, desde então, posto em causa. Vive-se, presentemente, um clima de tensão ideológica entre os jardineiros anglo-saxónicos e latinos, entre as escolhas 
conservadores ou democráticos, entre o capital ou social, entre a tese ou antítese, aparentemente sem definição à vista.

É neste quadro de desorientação generalizada, que se reflete uma grande dificuldade em mudar-se de paradigma. Para compreender melhor a reação dos jardineiros e meteorologistas portugueses e as dificuldades em responder-se a erros paradigmáticos, podemos recorrer às ideias de Thomas Kuhn. Kuhn (1962), tal como Kubler-Ross (1969) (1969), também não foi jardineiro ou meteorologista, mas antes um famoso físico, tendo publicado pela primeira vez o seu trabalho, agora reconhecido, onde aborda entre outros temas a natureza conservadora da ciência, o que provocou uma grande controvérsia. Kuhn (1962) argumentou que os académicos e cientistas, em vez de procurarem apenas a verdade tendem a ser altamente protetores do seu próprio trabalho e, portanto, conservadores por natureza. Embora Kuhn (1962) escrevesse sobre os físicos, o seu trabalho é aplicável noutras áreas. Kuhn (1962) argumentou que seus colegas físicos haviam construído as suas carreiras em torno de um paradigma particular e, portanto, profissionalmente tinham de rejeitar qualquer mudança de paradigma importante. Do ponto de vista de Kuhn (1962), os académicos bem-sucedidos são geralmente prisioneiros de seu próprio trabalho.

Por exemplo, se olharmos para a história, notamos que apesar do facto de Galileu ter provado claramente os movimentos da Terra nos seus estudos, a Igreja, porém, manteve, por razões próprias, a sua versão, recusando-se a admitir a mudança de paradigma, forçando mesmo Galileu a abjurar. Kuhn (1962) argumenta que o que era verdade, então, ainda é verdade atualmente. Assim, os cientistas e as corporações tendem a descartar qualquer anomalia em relação a longas crenças paradigmáticas como ameaças à carreira. Kuhn (1962) escreve sobre essa natureza conservadora da academia, quando afirma: Os paradigmas podem ser antes mais exigentes e mais completos do que qualquer outro conjunto de regras para a pesquisa que poderia ser captada de forma inequívoca a partir deles. A análise de Kuhn (1962) da natureza conservadora ou defensiva da academia, originou um grande debate no meio académico e tornou-se uma parte importante da pesquisa organizacional complexa. Os cientistas sociais vieram logo referir que os investigadores rejeitam com frequência anomalias paradigmáticas até que essas anomalias forcem os paradigmas estabelecidos a dar lugar ao nascimento de um novo paradigma. Kuhn (1962) escreve: Quanto mais precisos e de longo alcance forem os paradigmas, mais sensível é um indicador que sugere uma anomalia e, portanto, uma ocasião para a mudança de paradigma.

Assim, poder-se-á concluir que os jardineiros, agrónomos, meteorologistas, entre outros profissionais, tornaram-se tão apegados aos pressupostos que acabaram por entrar naquilo que podemos chamar de dados de negação, ignorando os factos inconvenientes para si e para as suas carreiras, recusando mudar. Pelo contrário, insistiram - ao que parece insistem ainda hoje - nos mesmos ideais sem considerar a evolução da fauna. De acordo com as razões invocadas por Kuhn, compreende-se que seja difícil mudar o paradigma, pelo que a solução talvez esteja no próprio ecossistema e na capacidade para se regenerar naturalmente. Desta forma, os jardineiros devem inspirar-se nos grandes parques selvagens como a savana africana ou, mesmo, a selva amazónia. Nestes grandes parques, os predadores e as presas coabitam e prosperam em plena liberdade numa flora exuberante, sem químicos, constituindo uma fauna mais justa do ponto de vista da luta das espécies pela sobrevivência e, consequente, fortalecimento e apuramento das raças em função dos mais fortes e capazes. Com uma intervenção excessiva ou, pior, com 
uma intervenção errada, correm-se sérios riscos de transformarmos os jardins da Europa num local específico para se manter animais selvagens e domesticados, num espaço circunscrito e em apertada vigilância, para poderem ser exibidos ao público, com o objetivo de preservar as espécies. Neste sistema, as espécies sobreviventes, muitas vezes não são as mais fortes e capazes, mas as mais protegidas, que não sobreviveriam em plena liberdade na selva, nem na savana.

\section{Referências}

Kubler-Ross, E. (1969). Sobre a morte e o morrer (4a ed.). São Paulo: Martins Fontes.

Kuhn, T. S. (1962). The Structure of Scientific Revolutions. Chicago: University of Chicago Press.

Lorenz, E. N. (1993). The Essence of Chaos. Washington: University of Washington Press. 